\title{
STUDI DESKRIPSI: PERILAKU ADIKSI HP (GADGET ADDICTION) PESERTA DIDIK DI SMP NEGERI 37 SURABAYA
}

\author{
Mirza Alvira \\ SMP Negeri 37 Surabaya dan e-mail: mirza.alvira.2010@gmail.com
}

\begin{abstract}
Abstrak
Indonesia menduduki peringkat empat didunia dalam hal penggunaan HP. Hal ini mengakibatkan munculnya perilaku adiksi. Perilaku adiksi ditemukan pada anak-anak usia sekolah yakni berkitar antara 13-19 tahun. Anak-anak menghabiskan waktu untuk bermain HP. Waktu mereka habis hanya untuk game, bermain media sosial, serta internet. Perilaku adiski HP ini memberikan pengaruh buruk bagi anak, khususnya minat dan prestasi belajar. Namun, disisi lain, perilaku adiksi HP juga memberikan pengaruh pada bidang emosi, sosial, fisik, dan psikis anak. Adiksi HP adalah perilaku ketergantungan anak pada HP. Anak dapat menghabiskan waktu berjam-jam hanya untuk bermain HP. Akivitas bermain HP tersebut cenderung mengarah pada kegiatan yang tidak bermanfaat bagi diri dan orang lain. Perilaku adiksi ini merupakan kondisi yang membutuhkan perhatian khusus untuk segera di atasi. Tujuan dari penelitian ini adalah untuk memperoleh gambaran tentang perilaku adiksi HP di kalangan anak-anak, mengetahui faktor penyebab munculnya, pengaruh buruk dari perilaku adiksi HP, dan tindakan yang dapat dilakukan untuk untuk mengurangi, mencengah, dan memperbaiki perilaku adiksi HP. Penelitian ini menggunakan metode penelitian studi deskriptif kualitatif. Subjek penelitiannya adalah siswa kelas 8 SMP Negeri 37 Surabaya. Sumber data dari penelitian ini adalah siswa (sumber primer), orang tua, guru, serta dokumen pendukung (sumber sekunder). Berdasarkan penelitian yang dilakukan dapat diketahui bahwa faktor utama penyebab munculnya perilaku adiksi HP adalah kontrol orang tua dalam memfilter penggunaan HP oleh anak, self control anak, self awareness anak, serta lingkungan. Faktor-faktor tersebut menyebabkan munculnya perilaku adiksi HP yang berbeda-beda di setiap anak. Selain faktor-faktor, hal yang ditemukan dari penelitian ini adalah dampak buruk dari perilaku adiksi HP. Dampak buruk yang paling banyak ditemukan di subjek penelitian adalah rendahnya minat dan prestasi belajar siswa. Selain itu, siswa memunculkan perilaku withdrawl (menarik diri) dari lingkungan. Perilaku adiksi HP dapat dicegah dan diperbaiki dengan berbagai cara dan berbagai teknik dengan bantuan banyak pihak. Saran untuk penelitian ini adalah melakukan kerja sama dengan orang tua dan pihak sekolah melakukan pengawasan kepada anak dalam penggunaan HP. Saran bagi peneliti selanjutnya adalah melakukan Penelitian Tindakan Kelas (PTK) atau penelitian eksperimen untuk mencoba melakukan konseling Mindfullness Cognitive Behavior Therapy (MCBT) dalam rangka mereduksi perilaku adiksi HP.
\end{abstract}

Kata Kunci: HP, adiksi, adiksi HP

\begin{abstract}
Indonesia is ranked fourth in the world in terms of gadget use. This results in the emergence of addictive behavior. Addictive behavior is found in school-age children between 13-19 years. Children spend time playing with gadget. Their time is spent only on games, playing social media, and the internet. This gadget adiski behavior has a bad influence on children, especially their interest and learning achievement. However, on the other hand, gadget addiction behavior also affects the emotional, social, physical, and psychological fields of children. Gadget addiction is a child's dependency on gadget. Children can spend hours just playing on gadget. The activity of playing the gadget tends to lead to activities that are not useful for oneself and others. This addictive behavior is a condition that requires special attention to be overcome immediately. The purpose of this study was to obtain an overview of cellphone addiction behavior among children, to find out the factors causing the appearance, the bad effects of gadget addiction behavior, and actions that can be taken to reduce, distract, and improve gadget addiction behavior. This research uses a qualitative descriptive study research method. The research subjects were 8th grade students of SMP Negeri 37 Surabaya. Sources of data from this study are students (primary sources), parents, teachers, and supporting documents (secondary sources). Based on the research conducted, it can be seen that the main factors causing the emergence of gadget addiction behavior are parental control in filtering the use of gadget by children, children's self-control, children's self-awareness, and the environment. These factors cause the emergence of different gadget addiction behavior in each child. Apart from these factors, what was found from this study was the adverse effects of gadget addiction behavior. The most common adverse effects found in research subjects were low student interest and achievement. In addition, students bring out withdrawal behavior from the environment. gadget addictive behavior can be prevented and repaired in various ways and
\end{abstract}


various techniques with the help of many parties. The suggestion for this research is to collaborate with parents and the school to supervise children in using gadgets. Suggestions for the next researcher are to conduct Classroom Action Research or experimental research to try to do Mindfulness Cognitive Behavior Therapy (MCBT) counseling in order to reduce gadget addiction behavior.

Keywords: gadget, addiction, gadget addiction

\section{PENDAHULUAN}

Kecenderungan meningkatnya kasus anak kecanduan HP tersebut terkait dengan tingginya penetrasi internet di Indonesia. Internet menjadi bagian penting dalam kehidupan sehari-hari (Hassan, dkk, 2020). Berdasarkan Survei Asosiasi Penyelenggara Jasa Internet Indonesia (APJII) tahun 2017, sebanyak 143,26 juta orang atau 54,68 persen dari populasi Indonesia menggunakan internet Penetrasi pengguna internet terbesar di usia 1318 tahun (75,50 persen). HP adalah perangkat yang paling banyak dipakai untuk mengakses internet $(44,16$ persen). Menteri Komunikasi dan Informatika Rudiantara dalam acara Internet Aman untuk Anak di Jakarta, 6 Februari 2018, mengungkapkan, sebanyak 93,52 persen penggunaan media sosial oleh individu Indonesia berada di usia 9-19 tahun dan penggunaan internet oleh individu sebanyak 65,34 persen berusia 9-19 tahun. Umumnya anak-anak menggunakan internet untuk mengakses media sosial, termasuk Youtube dan game online (Kompas, 2018).

Berdasarkan Kajian Penggunaan Media Sosial oleh Anak dan Remaja yang diterbitkan Pusat Kajian Komunikasi (Puskakom). Universitas Indonesia 2017, anak-anak dan remaja tertarik mengakses media sosial karena mempertemukan kembali diri mereka dengan teman-teman dan keluarga yang terpisah jarak, untuk berbagi pesan. Adapun mereka mengakses game online untuk memenuhi hasrat mereka dalam bermain di dunia maya dan untuk mengkoping stres (Kuss dan Griffiths, 2012).

Penggunaan HP untuk bermain game online, youtube, internet, dan media sosial juga dialami oleh anak-anak di usia SMP. Anak-anak di SMP Negeri 37 Surabaya lebih banyak menggunakan HP untuk bermain game online dan media sosial daripada untuk mengikuti pembelajaran daring. Hal ini terbukti dari jumlah partisipasi peserta didik yang mengikuti meet di setiap Mata Pelajaran. Peserta didik yang mengikuti meet pada setiap mata pelajaran hanya seperempat dari jumlah peserta didik setiap kelas.

Kondisi tersebut, tidak hanya terjadi pada satu kelas, namun juga terjadi di semua kelas 8 . Ketidakmampuan anak untuk berpartisipasi aktif dalam kegiatan pembelajaran disebabkan karena perilaku anak yang mengalami kecanduan penggunaan HP untuk game online ataupun bermain media sosial. Perilaku kecanduan hp sering dikenal dengan istilah adiksi HP (gadget addiction). Perilaku adiksi HP adalah perilaku yang berlebihan yang dialami oleh anak. Namun, anak tidak menyadari bahwa apa yang telah dilakukan memberikan dampak buruk bagi diri dan orang lain. Kurangnya self awareness pada diri anak, semakin menumbukan perilaku adiksi HP pada diri anak.
Gadget atau HP merupakan teknologi modern sebagai penentu utama status sosial ekonomi di kalangan setiap orang baik anak, anak, remaja, maupun orang dewasa (Bhattacharyya, 2015). Selain gadget, teknologi modern lainnya adalah laptop, Ipad, Iphone, game, Play Station, dan lainnya. Keberadaan teknologi modern tersebut menimbulkan pengaruh baik dan buruk (Muduli, 2014). Perbedaan pengaruh terjadi karena tergantung pada cara penggunaan teknologi dalam kehidupan sehari-hari (Susilawati, 2019).

Dampak positif dari teknologi khususnya gadget adalah meningkatkan modernisasi masyarakat untuk dapat mengikuti perkembangan jaman, mengakses informasi dari berbagai negara di belahan dunia (Chasanah dan Kilis, 2017), menciptakan kreativitas dalam menjalankan usaha, serta memberikan kemudahan peserta didik untuk mendapatkan sumber belajar yang beraneka ragam. Dampak positif dari gadget dapat dirasakan oleh semua orang di berbagai sektor kehidupan, khususnya di sektor pendidikan. Kegiatan belajar dan pembelajaran dalam dilakukan dengan cepat dan mudah dengan adanya bantuan gadget.

Gadget tidak hanya memberikan dampak positif bagi penggunanya (Pratama, dkk, 2020). Gadget dapat memberikan dampak negatif, jika salah dalam penggunaannya (Nursikuwagus, dkk, 2020). Gadget dapat memicu munculnya perilaku adiksi. Perilaku adiksi dapat dialami oleh setiap orang, mulai dari anak-anak sampai pada orang dewasa. Adiksi HP yang dialami anak-abak maupun orang dewasa meliputi game onlie, youtube, internet, situs dewasa, maupun media sosial (Kwon, dkk, 2013).

Perilaku adiksi adalah ketergantungan pada teknologi modern yang mempunyai konsekuensi yang besar bagi anak-anak di masa sekolah. Perilaku adiksi dikategorikan sebagai perilaku ganguan kontrol impuls. Menurut American Psychiatric Association's (2020, dalam Daria J \& Mark D, 2011) ciri khas dari gangguan kontrol implus adalah kegagalan untuk menahan dorongan dan godaan untuk melakukan tindakan bagi diri sendiri dan orang lain. Adiksi merupakan sindrom ketergantungan. APA (2020 dalam Daria J \& Mark D, 2011) menyebutkan bahwa adiksi merupakan sekelompok kognitif, perilaku, dan gejala fisiologis yang menunjukkan bahwa individu mengalami ketergantungan pada suatu zat atau objek tertentu.

Istilah adiksi atau pembiasaan sekarang dikenal dengan istilah dependen atau ketergantungan. Adiksi gadget merupakan kecanduan non-zat adiktif terbesar di abad 21. Kecanduan dalam penggunaan gadget sering di kenal dengan adiksi HP (gadget addiction). Gadget addiction adalah pemakaian gadget secara berlebihan (Sussman dan Sussman, 2011) yang ditandai dengan gejala-gejala klinis kecanduan, seperti keasyikan dengan 
objek candu, pemakaian yang lebih sering terhadap objek candu, tidak memperdulikan dampak fisik maupun psikologis pemakaian dan sebagainya (Abdel-Salam, 2019).

Kecanduan mengacu pada dorongan tak tertahankan yang sering disertai dengan hilangnya kendali. Penelitian tentang dampak kecanduan internet pada dewasa muda berada dalam tahap awal perkembangan (Joseph, 2016). Di negara india, orang tua mengeluh karena putra putri mereka mengalami kecanduan pada penggunaan HP dan hanya untuk bermain game (Bhattacharyya, 2015). Prevalensi kecanduan gadget sangat bervariasi diantara negara dan berbanding terbalik dengan kualitas hidup.

Istilah adiksi atau pembiasaan sekarang dikenal dengan istilah dependen atau ketergantungan. Adiksi gadget merupakan kecanduan non-zat adiktif terbesar di abad 21. Prevalensi adiksi 10\% anak usia 11-14 tahun. Di india prevalensinya 39-44\%. Dikorea 4.9-10\%. Sekitar $70 \%$ orang menggunakan ponsel mereka dalam satu jam pertama bangun di pagi hari. 56\% subjek memeriksa ponsel mereka sebelum pergi tidur. 51\% memeriksa ponsel mereka secara konstan selama liburan (Bhattacharyya, 2013). Prevalensi adiksi gadget di kuatkan dengan hasil studi Abdel-Salam (2013) yang menjelaskan bahwa remaja di Arab Saudi mengalami adiksi gadget khususnya penggunaan internet sebesar $45.3 \%$.

Berdasarkan penelitian sebelumnya oleh Young et al tentang adiksi internet (Young 2015), ada dua puluh pertanyaan atau konstruksi yang dapat menunjukkan seseorang yang kecanduan internet. Berdasarkan dua puluh pertanyaan, kami mengklasifikasikan menjadi empat kategori seperti "waktu", "hubungan", "produktivitas", dan "pemikiran (M.Oktaviano, dkk, 2020). Empat hal tersebut menjadi kunci utama untuk menentukan seorang anak mengalami adiksi atau tidak.

Perilaku adiksi juga tidak mampu untuk mengurangi atau menghentikan penggunaan barang secara langsung. Roger \& McMillins (1991) mengatakan bahwa adiksi dapat digolongkan sebagai suatu penyakit yang memiliki kriteria sebagai berikut: 1) penyakit primer, 2) tidak mempunyai kondisi awal yang menunjukkan adanya adiksi, 3) kondisi berulang dan dapat kambh kapan saja jika tidak diimbangi dengan self control, 4) memberikan pengaruh secara fisik dan psikis, 5) menimbulkan dampak keberlanjutan baik secara fisik, psikologis, emosi, dan sosial) (Humas BNN, 2013).

Penelitian ini mempunyai tiga tujuan yang ingin dicapai. Pertama, penelitian bertujuan untuk memperoleh gambaran tentang perilaku adiski HP yang dialami anakanak. Kedua, penelitian ini bertujuan untuk menemukan faktor-faktor yang menyebabkan munculnya perilaku adiksi HP. Ketiga, penelitian bertujuan untuk menemukan dampak buruk dari perilaku adiksi HP.

\section{METODE}

Rancangan penelitian yang digunakan dalam penelitian ini adalah studi deskriptif kualitatif. Peneliti memaparkan kondisi dan fenomena nyata tentang adiksi gadget yang terjadi pada anak-anak. Subjek penelitian yakni peserta didik kelas 8 SMP Negeri 37 Surabaya. Subjek penelitian ini dipilih berdasarkan tujuan penelitian, sehingga pemilihannya dilakukan secara purposive sampling.

Sumber data pada penelitian ini ada dua, yakni 1) sumber primer, 2) sumber sekunder. Sumber primer adalah sumber utama dari penelitian. Sumber primer pada penelitian ini adalah peserta didik kelas 8 SMP Negeri 37 Surabaya. Sumber sekunder pada penelitian ini adalah guru, orang tua, serta dokumen pendukung. Teknik yang digunakan untuk pengumpulan data adalah wawancara, observasi, dan studi dokumentasi.

Peneliti menjadi alat pengumpul data utama. Peneliti mempunyai andil besar dalam pemerolehan informasi dari semua sumber data. Peneliti mengumpulkan data tentang adiksi gadget selama tiga bulan. Data yang diperoleh dari kegiatan peneliti dianalisis untuk mendapatkan data yang valid. Data yang valid tersebutlah yang dapat memberikan gambaran jelas tentang perilaku adiksi gadget yang dialami oleh peserta didik

Analisis data pada penelitian kualitatif ini dilakukan melalui tiga tahap, yakni: 1) mengumpulkan data, 2) menganalisis data/mengtranskripsikan data, 3) mengkoding data (Creswell, 2012: 237). Peneliti mengumpulkan semua data yang diperoleh dari berbagai sumber dan berbagai teknik pengumpulan data. Setelah data tentanga diksi gadget di peroleh, peneliti menganalisis setiap data yang diperoleh. Peneliti melakukan reduksi data yang tidak relevan dengan penelitian. Data yang digunakan dan dipertahankan adalag data yang relevan dan mendukung adiksi gadget. Setelah data-data tersebut dianalisis, maka peneliti melakukan pengkodingan data. Pengkodingan bertujuan untuk memudahkan peneliti dalam pengelompokkan data yang diperoleh dari berbagai sumber dan teknik pengumpulan data tersebut.

\section{HASIL DAN PEMBAHASAN}

Berdasarkan hasil wawancara peneliti dengan sumber primer secara langsung dapat diperoleh data bahwa adiksi gadget yang dialami oleh anak-anak mempunyai bentuk yang berbeda-beda. Adiksi gadget yang dialaminya adalah adiksi gadget untuk bermain game, meliat situs dewasa, dan bermain media sosial (facebook, group WA (Fansbase), Instagram, Tiktok). Jenis adiksi gadget yang mempunyai presentase tinggi adalah adiksi gadget untuk bermain game online dan bermain media sosial.

Berdasarkan wawancara dengan anak-anak secara tidak langsung yakni melalui media meet di microsoft 365, ditemukan bahwa setiap anak mempunyai game di gadgetnya. Game yang paling banyak dimainkan adalah Mobile Lagend (ML), Free Fair (FF), dan Pop-G. Adiksi gadget untuk bermain game tidak lagi memandang gender. Adiksi ini tidak hanya dialami oleh anak laki-laki, tetapi juga dialami oleh anak perempuan.

Berdasarkan hasil wawancara dengan guru selaku wali kelas $8 \mathrm{~A}$ sampai denga $8 \mathrm{~J}$ juga diperoleh data yang sama. Dari $\leq 40$ peserta didik di setiap kelas, hampir setengah dari jumlah peserta didik telah mempunyai gadget. Gadget lebih banyak digunakan untuk bermain game dan medsos dari pada untuk kegiatan pembelajaran. Selain dari 
kegiatan wawancara, data tentang adiksi gadget juga diperoleh dari kegiatan observasi peneliti. Peneliti menemukan bahwa, pembelajaran daring melalui meet microsoft 365 hanya diikuti oleh 7-10 anak pada setiap kelasnya. Jumlah ini tidak sebanding dengan jumlah siswa yang mempunyai gadget per kelas. Kondisi ini disebabkan karena anak-anak menggunakan gadget untuk game online dan medsos, sehingga mereka lupa untuk mengikuti kegiatan pembelajaran daring.

Berdasarkan kondisi diatas, dapat diketahui bahwa gadget memberikan dampak buruk pagi peserta didik. Dampak buruk perilaku adiksi gadget adalah rendahnya minat belajar anak. Hal ini dibuktikan dengan minimnya partisipasi peserta didik dalam mengikuti kegiatan pembelajaran daring. Selain itu, bukti lain yang menunjukkan rendahnya minat untuk belajara adalah nilai yang diperoleh peserta didik pada setiap mapel saat Ulangan Harian maupun Penilaian Tengah Semester. Peserta yang mendapatkan nilai di atas KKM hanya 25\% pada masing-masing kelas. Hal ini menunjukkan bahwa semakin rendah minat belajar peserta didik, maka semakin rendah pula prestasi belajar peserta didik.

Diseluruh sistem pendidikan di seluruh dunia, prestasi belajar merupakan indikator utama dari keberhasilan dari aktivitas pendidikan. Pretasi belajar dipengaruhi banyak faktor seperti kepribadian (faktor internal) dan faktor lingkungan (faktor eksternal) (Haghbin, dkk, 2013). Salah satu faktor tersebut adalah adiksi gadget. Seseorang yang mengalami adiksi gadget, membutuhkan waktu dalam jumlah yang besar untuk memainkannya. Anak-anak lalai dengan tugas lain yang seharusnya dilakukan. Anak yang menggunakan waktu hanya untuk bermain gadget akan mengalami ketergantungan. Anak-anak mengalami kesulitan untuk melepaskan diri dari gadget.

Dampak buruk lainnya dari perilaku tersebut adalah rendahnya keterampilan sosial anak. Anak menjadi enggan untuk berkomunikasi dengan orang lain (Haghbin, dkk, 2013). Sikap enggan tersebut, memunculkan perilaku menarik diri dari lingkungan. Anak-anak hidup dengan dunia mereka sendiri tanpa memperdulikan lingkungan sekitar. Nasrallad mengatakan bahwa sebagai pengaruh media elektronik, anak-anak memiliki lebih sedikit ruang untuk berpartisipasi di dunia nyata. Berdasarkan beberapa penelitian, anak usia 0-2 tahun tidak boleh terkena gadget, anak usia 3-5 tahun lama dibatasi hanya 1 jam per hari, dan 2 jam per hari untuk anak usia 6-18 tahun. Fakta di lapangan menunjukkan banyak anak yang menggunakan gadget 4-5 kali lebih banyak dari jumlah yang disarankan.

Dampak lainnya adalah kecerdasan manusia berorientasi pada teknologi, kesehatan psikologis menurun, menarik diri dari lingkungan (withdrawl) (Rugai, dkk, 2016), menambah kecelakaan, gangguan tidur, peningkatan stres, berkurangnya kemampuan untuk mengontrol emosi (Kumar, dkk, 2018), dan menurunkan kemampuan berpikir atau Anak-anak di India bisa dikatakan sebagai "Budak Gadget" Menurut Michael Condry (kepala operasi dan petugas pengembangan game) (Bhattacharyya, 2015). Hal ini terjadi karena anak-anak lemah pada kemampuan self control (kontrol diri). Berdasarkan dampak buruk yang diuraikan tersebut, dapat disimpulkan bahwa adiksi gadget dapat memberikan dampak bagi kesehatan fisik dan psikis anak-anak (Wong, 2016)

Di era digital sekarang ini, perkembangan teknologi dapat memberikan kesempatan kepada anak-anak untuk mengakses segala informasi secara online dengan cepat dan mudah (King, dkk, 2013). Gadget memainkan peran pendukung dalam gaya hidup saat ini.

Penggunaan media sosial, Indonesia menduduki nomor empat tertinggi di dunia. Berdasarkan data dari KOMINFO pada tahun 2014 angka penggunaan gadget di indonesia sangat tinggi (Suhana, 2018). Penggunaan media sosial tidak hanya berdampak positif tetapi berdampak negatif pula seperti masalah mental dan perilaku (Suhana, 2018), penurunan motivasi akademik. Dampak negatif tersebut menjadi ancaman bagi anak-anak dan remaja. Oleh karena itu perlu diketahui faktor-faktor munculnya perilaku adiksi gadget di Indonesia. Hal ini dilakukan untuk membantu mengurangi jumlah dan tingkat adiksi gadget di Indonesia.

Semakin berkembangnya teknologi, maka semakin berkembang pula perilaku adiksi. Tindakan yang perlu dilakukan untuk mengantisipasi berkembangnya perilaku adisksi adalah melatih kontrol diri pada anak-anak. Kotrol diri yang baik akan membantu anak-anak untuk mengontrol perilaku. Kemampuan kontrol diri yang baik pada diri anak, membantu anak untuk dapat menentukan perilaku yang tepat dan tidak tepat serta berlebihan dan tidak berlebihan. Tindakan lain yang dapat dilakukan untuk mencengah berkembangnya perilaku adiksi adalah filter keluarga dalam pemilihan situs intenet anak untuk menghindari efek buruk dari penggunaan gadget. Selain kedua tindakan di atas, tindakan yang dapat dilakukan untuk membantu mereduksi perilaku adiksi HP pada anak adalah melalui kegiatan konseling dengan teknik Mindfulness Cognitive Behavioral Therapy (Shonin, dkk, 2014).

\section{PENUTUP}

\section{Simpulan}

Penggunaan gadget secara bijak perlu dilatihkan kepada anak-anak. Penggunaan secara bijak, dapat memberikan dampak positif kepada anak dan sebaliknya. Anak-anak akan mendapatkan dampak yang negatif, jika salah dalam menggunakannya. Kesalahan dalam pemanfaatan gadget akan memunculkan perilaku adiksi gadget. Adiksi gadget adalah aktivitas atau perilaku yang dilakukan secara berulang-ulang dan akan menimbulkan dampak negatif jika perilaku tersebut tidak dapat dikontrol.

Adiksi gadget dapat memberikan dampak baik secara fisik maupun secara psikis. Hal ini disebabkan karena perilaku adiksi gadget memungkinkan anak untuk menggunakan banyak waktu untuk bermain gadget. Era globalisasi sekarang ini, memberikan akses kepada anakanak khususnya anak-anak di usia SMP untuk mendapatkan infromasi secara cepat. Pada anak usia remaja, mereka akan cenderung lebih mudah mempelajari sesuatu hal yang berkaitan dengan gadget dibandingkan dnegan orang dewasa. Hal tersebut dikarenakan pada perkembangan anak usia remaja mempunyai rasa ingin 
tahu yang lebih besar dibandingkan dengan orang dewasa. Hal tersebut dikarenakan anak-anak mempunyai kemampuan adaptasi yang cepat dengan teknologi baru. Anak-anak menjadi lebih terampil dalam menggunakan gadget daripada orang dewasa. Kemampuan adaptasi yang baik tersebut harus diimbangi dengan kemampuan self control (kontrol diri) pada anak dan keterlibatan keluarga khususnya orang tua untuk memfilter penggunaan gadget anak. Tindakan ini dilakukan untuk mencegah adanya perilaku adiksi gadget pada anak.

\section{Saran}

Berdasarkan kesimpulan dari kegiatan penelitian ini, diketahui bahwa perilaku adiksi gadget di kalangan anakanak khususnya di SMP Negeri 37 Surabaya telah melebihi batas normal. Gadget telah memberikan dampak buruk bagi anak-anak. Dampak buruk tersebut tidak hanya dibidang belajar, tetapi juga di bidang sosial, emosi, fisik, dan psikis mereka. Perilaku adiksi gadget perlu mendapatkan perhatian khusus dari berbagai pihak, dalam rangka mengurangi bahkan menghilangkan adiksi gadget pada diri anak. Saran yang bisa diberikan peneliti untuk membantu mengatasi perilaku adiksi gadget diantaranya adalah:

1. Keterlibatan orang tua dalam mengontrol penggunaan gadget sangat diperlukan.

2. Orang tua menerapkan "no gadget time" atau tidak menggunakan gadget pada saat-saat tertentu, misalnya saat liburan atau waktu berkumpul dengan keluarga. Harapannya, anak tetap dapat berinteraksi dengan anggota keluarga lain dan tidak hanya terfokus pada gadget-nya.

3. Pemberian informasi pihak sekolah kepada orang tua terkait perkembangan anak diperlukan untuk membantu orang tua memantau kondisi anak.

4. Guru BK atau konselor dapat memberikan layanan informasi dalam rangka memberikan pemahaman bagi anak-anak yang belum mengalami adiksi dan pencegahan bagi anak-anak yang mengalami adiksi gadget katagori rendah.

5. Guru BK dan konselor memberikan layanan konseling individu kepada anak yang mengalami adiksi gadget kategori tinggi dengan konseling Mindfullness Cognitive Behavior Therapy (MCBT). Konseling ini bisa menjadi saran bagi peneliti selanjutnya untuk menguji keefektifan MCBT dalam mereduksi perilaku adisksi gadget pada anak usia SMP.

\section{DAFTAR PUSTAKA}

Abdel-Salam, Doaa m., Alrowaili, Hajar i., Albedaiwi, Haifa K., Alessa, Amnah L., dan Alfayyadh, Hanan A. 2019. Prevalence Of Internet Addiction And Its Associated Factors Among Female Students At Jouf University. Journal Saudi Arabia. 94 (12). Hal:1-8.

Bhattacharyya, Ranjan. 2015. Addiction to Modern Gadgets and Technologies Across Generations. Eastern Journal of Psychiatry. 18 (2): Hal: 27-37.
Chasanah, Annisa Maulidya., dan Kilis, Grace. 2017. Adolescents' Gadget Addiction and Family Functioning. Advances in Social Science. Education and Humanities Research. 139. Hal: 350-358.

Creswell, John W. 2012. Educational Research (Planning, Conducting, and Evaluating Quantitative and Qualitative Research) Fourth Edition. Pearson Education: Boston.

Haghbin, Maryam., Shaterian Fatemeh, Hosseinzadeh, Davood., Griffiths, Mark D. 2013. A brief report on the relationship between self-control, video game addiction and academic achievement in normal and ADHD students. Journal of Behavioral Addictions: 2 (4). Hal: 239-243.

Hasan, Tubayesha., Alam, Mohammad Morshad., Whab, Abrar., Hawlader, Mohammad Delwer. 2020. Prevalence and associated factors of internet addiction among young adults in Bangladesh. Hassan et al. Journal of the Egyptian Public Health Association. 95 (3). Hal: 2-8.

Humas BNN. 2013. Mengenal Adiksi. https://bnn.go.id/mengenal-adiksi/, diakses tanggal 15 April 2021

King, Daniel L., Gainsbury, Sally M., Delfabbro, Paul H., Hing, Nerilee., dan Abarbanel, Brett. 2015. Distinguishing between gaming and gambling activities in addiction research. Journal of Behavioral Addictions. 4(4). Hal: 215-220.

Kompas. 2018. https://kominfo.go.id/content/detail/135-

47/kecanduan-gawai-ancam-anak-

anak/0/sorotan_media, diakses tanggal 15 April 2021.

Kumar, Aravind K., Sherkhane, Mayur S. 2018. Assessment of gadgets addiction and its impact on health among undergraduates. International Journal of Community Medicine and Public Health. 5 (8). Hal: 3624-2628.

Kuss, Daria J., Griffiths, Mark D. 2011. Online gaming addiction in children and adolescents: A review of empirical research. Journal of Behavioral Addictions. 1(1). Hal: 3-22.

Kwon, Min., Kim, Dai-Jin., Cho, Hyun., dan Yang, Soo. 2013. The Smartphone Addiction Scale: Development and Validation of a Short Version for Adolescents. Journal PLOS One. 8 (12). Hal: 1-7.

Muduli, Jyoti Ranjan 2014. Addiction to Technological Gadgets and Its Impact on Health and Lifestyle: A Study on College Students. Department of Humanities and Social Sciences National Institute of Technology, Rourkela, India.

Nursikuwagus, A., Hikmawati, E., Wisesty, U.S., Munggana, W., dan Mahayana, D. 2020. Kajian Saintifik Fenomena Adiksi Gadget dan Media 
Sosial di Indonesia. Jurnal Teknologi dan Informasi (JATI). 10 (1). Hal: 25-39.

Pratama, M. Octaviano., Harinitha, Dwi., Indriani, Susmini., dan Denov, Bryan. 2020. Influence Factors of Social Media and Gadget Addiction of Adolescent in Indonesia. Jurnal Sistem Informasi (Journal of Information System). 16 (1). Hal: 1624.

Rugai, Joseph., dan Ekeke, Joy Telu Hamiliton. 2016. A Review of Digital Addiction: A Call for Safety Education. Journal of Education and e-Learning Research. 3 (1). Hal: 17-22.

Shonin, Edo., Gordon, William Van., dan Grifftha, Mark D. 2014. Mindfulness as a Treatment for Behavioural Addiction. Research \& Therapy. 5 (1): Hal: 1-2.

Suhana, Mildayani. 2017. Influence of Gadget Usage on Children's Social-Emotional Development. Advances in Social Science, Education and Humanities Research (ASSEHR). 169. Hal: 224227.

Susilowati, E. 2019. The Influence of Gadget towards Information Technology Addict and Procrastination Behaviour. IOP Conference Series: Materials Science and Engineering.

Sussman, Steve., dan Sussman, Alan N. 2011. Considering the Definition of Addiction. International Journal of Environmental Research and Public Health. 8. Hal: 4025-4038.

Wong, Irene Lai Kuen., dan Lam, Millicent Pui Sze. 2016. Gaming behavior and addiction among Hong Kong adolescents. Asian $J$ of Gambling Issues and Public Health. 6 (6). Hal: 1-16. 